\title{
GENETIC HETEROGENEITY OF FAMILIAL HYPOURICEMIA DUE TO ISOLATED RENAL TUBULAR DEFECT
}

\author{
Tomokazu SuzukI, Kinichi KIDOGUCHI, and Akira HAYASHI \\ The Third Department of Internal Medicine, Osaka University Hospital, \\ Fukushima-ku, Osaka 553, Japan
}

\begin{abstract}
Summary A Japanese kindred afflicted with familial hypouricemia due to isolated renal tubular defect is reported. The propositus was fortuitously found to have a low serum uric acid concentration $(0.9 \mathrm{mg} / \mathrm{dl})$. Based on the effect of pyrazinamide and probenecid on his renal clearance of uric acid, it is suggested that the defect is probably at the presecretory reabsorption site. A survey of the available members of his family (23 in 4 generations) revealed that the condition is transmitted in an autosomal dominant mode. Genetic evidence suggests that tubular presecretory reabsorption of uric acid in man is under the control of at least two autosomal loci.
\end{abstract}

\section{INTRODUCTION}

Familial hypouricemia due to isolated renal tubular defect is a rare benign condition (De Vries and Sperling, 1979). Although it has almost no clinical significance, it is an important genetic probe to elucidate the mechanism for renal tubular urate handling (Rieselbach, 1977). Based on the magnitude of renal urate clearance and the effects on it of pyrazinamide and probenecid, two types have been distinguished: one due to defective pre-secretory and the other to combined defective pre-secretory and post-secretory tubular urate reabsorption. The mode of inheritance in both is autosomal, probably recessive.

We describe a Japanese family afflicted with autosomal dominant familial hypouricemia due to an isolated defect in pre-secretory reabsorption of urate, and discuss genetic heterogeneity of the condition.

\section{CASE REPORT}

The propositus, A.Y., was a 33-year old laboratory worker of a pharmaceutical company when he was fortuitously noticed during a regular medical examination for workers handling organic solvents. Physical examination was not remarkable.

Received August 14, 1981 
He enjoyed good health all his life and took no medication.

He had a plasma uric acid level of $0.9 \mathrm{mg} / \mathrm{dl}$, as measured by the phosphotungstic acid method. Other blood chemistry values were normal: sodium, 142 $\mathrm{mEq} / \mathrm{liter}$; potassium, $3.7 \mathrm{mEq} /$ liter; chloride, $104 \mathrm{mEq} / \mathrm{liter}$; calcium, $9.5 \mathrm{mg} / \mathrm{dl}$; inorganic phosphate, $2.6 \mathrm{mg} / \mathrm{dl}$; iron, $134 \mu \mathrm{g} / \mathrm{dl}$; copper, $88 \mu \mathrm{g} / \mathrm{dl}$; urea nitrogen, $12 \mathrm{mg} / \mathrm{dl}$; creatinine, $0.8 \mathrm{mg} / \mathrm{dl}$; and cholesterol, $139 \mathrm{mg} / \mathrm{dl}$. Serum protein was $7.2 \mathrm{~g} / \mathrm{d} 1$, with an almost normal pattern. Liver function tests, routine urinalysis, urinary excretion of 10 amino acids, roentgenograms of the chest, spine, and long bones were all normal.

His parents were not consanguineous. His father died of chronic renal insufficiency and Stokes-Adams syndrome at age 58 years. On admission to Fukushima Rosai Hospital at age 56 years, his serum urate concentration was $10.8 \mathrm{mg} / \mathrm{dl}$, which was subsequently reduced to normal levels $(4.1-5.6 \mathrm{mg} / \mathrm{dl})$ with hemodialysis. Autopsy revealed glomerulonephritic nephrosclerosis and renal stone in left pelvis. No other family members had suffered from urinary tract stones or bone disease. For the study of the mode of inheritance, serum of 23 family members were analyzed for uric acid.

\section{METHODS}

Throughout the study, uric acid in serum and urine was determined by the phosphotungstic acid method. Renal clearances of uric acid and creatinine were measured by the method of Nakamura (1979). Urate clearances were measured before and after oral administration of $3.0 \mathrm{~g}$ pyrazinamide and $1.0 \mathrm{~g}$ probenecid on different days, and the various parameters of urate handling were calculated according to Steele and Rieselbach (1967).

\section{RESULTS}

Five different determinations of serum urate concentrations in the propositus ranged from 0.7 to $0.9 \mathrm{mg} / \mathrm{dl}$ (mean of $0.8 \mathrm{mg} / \mathrm{d} 1$ ). His serum hypoxantine and xantine concentrations were 0.33 and $0.06 \mu \mathrm{g} / \mathrm{ml}$ respectively. The urinary excretion of uric acid was 550 to $720 \mathrm{mg} /$ day; of calcium, 120 to $131 \mathrm{mg} /$ day; of inorganic phosphate, $677 \mathrm{mg} /$ day; and of magnesium, $1.6 \mathrm{mg} /$ day.

Data from the pyrazinamide suppression test are summarized in Table 1. Compared with a normal subject, renal clearance of uric acid in the propositus was markedly increased $(39 \mathrm{ml} / \mathrm{min}$ ) in the control period and was only minimally suppressed by pyrazinamide to $35 \mathrm{ml} / \mathrm{min}$. A transient increment of urate clearance was observed.

Data from the probenecid test are summarized in Table $\cdot 2$. While renal clearance of uric acid in a normal subject was increased 6.5-fold following administration of probenecid, it was increased only 2.1 -fold in the propositus. 
Table 1. Effect of pyrazinamide ( $3.0 \mathrm{~g}$, p.o.) on uric acid excretion.

\begin{tabular}{|c|c|c|c|c|c|}
\hline $\begin{array}{c}\text { Period } \\
\text { (min) }\end{array}$ & $\underset{(\mathrm{mg} / \mathrm{dl})}{\operatorname{Pur}}$ & $\underset{(\mathrm{mg} / \mathrm{min})}{\operatorname{UurV}}$ & $\underset{(\mathrm{ml} / \mathrm{min})}{\operatorname{Cur}}$ & $\underset{(\mathrm{ml} / \mathrm{min})}{\operatorname{Ccr}}$ & $\underset{(\%)}{\operatorname{Cur}: \text { Cor }}$ \\
\hline \multicolumn{6}{|c|}{ Propositus (A.Y.) } \\
\hline-60 to 0 & 0.9 & 0.40 & 39.3 & 139.6 & 28.2 \\
\hline 0 to 60 & 0.7 & 0.41 & 51.2 & 99.5 & 51.5 \\
\hline \multicolumn{5}{|c|}{ Control (T.S.) } & 42.1 \\
\hline-60 to 0 & 7.6 & 0.38 & 4.35 & 76.4 & 5.7 \\
\hline 0 to 60 & 7.8 & 0.12 & 1.39 & 85.1 & 1.6 \\
\hline 60 to 120 & 8.1 & 0.03 & 0.36 & 85.0 & 0.4 \\
\hline
\end{tabular}

Pur, serum uric acid concentration; UurV, urinary excretion of uric acid; Cur and Ccr, renal clearances of uric acid and creatinine.

Table 2. Effect of probenecid (1.0 g, p.o.) on uric acid excretion.

\begin{tabular}{|c|c|c|c|c|c|}
\hline $\begin{array}{l}\text { Period } \\
\text { (min) }\end{array}$ & $\underset{(\mathrm{mg} / \mathrm{dl})}{\text { Pur }}$ & $\underset{(\mathrm{Ug} / \mathrm{min})}{\mathrm{UurV}}$ & $\underset{(\mathrm{ml} / \mathrm{min})}{\mathrm{Cur}}$ & $\underset{(\mathrm{ml} / \mathrm{min})}{\operatorname{Ccr}}$ & $\begin{array}{c}\text { Cur : Ccr } \\
(\%)\end{array}$ \\
\hline \multicolumn{6}{|c|}{ Propositus (A.Y.) } \\
\hline-60 to 0 & 0.7 & 0.37 & 43.9 & 146.1 & 30.0 \\
\hline 0 to 60 & 0.7 & 0.78 & 96.4 & 125.3 & 76.9 \\
\hline \multicolumn{6}{|c|}{ Control (T.S.) } \\
\hline-60 to 0 & 7.8 & 0.40 & 4.51 & 70.9 & 6.4 \\
\hline 0 to 60 & 7.5 & 1.54 & 17.84 & 90.0 & 19.8 \\
\hline 60 to 120 & 6.8 & 2.28 & 29.19 & 88.4 & 33.0 \\
\hline
\end{tabular}

For further explanation see legend of Table 1.

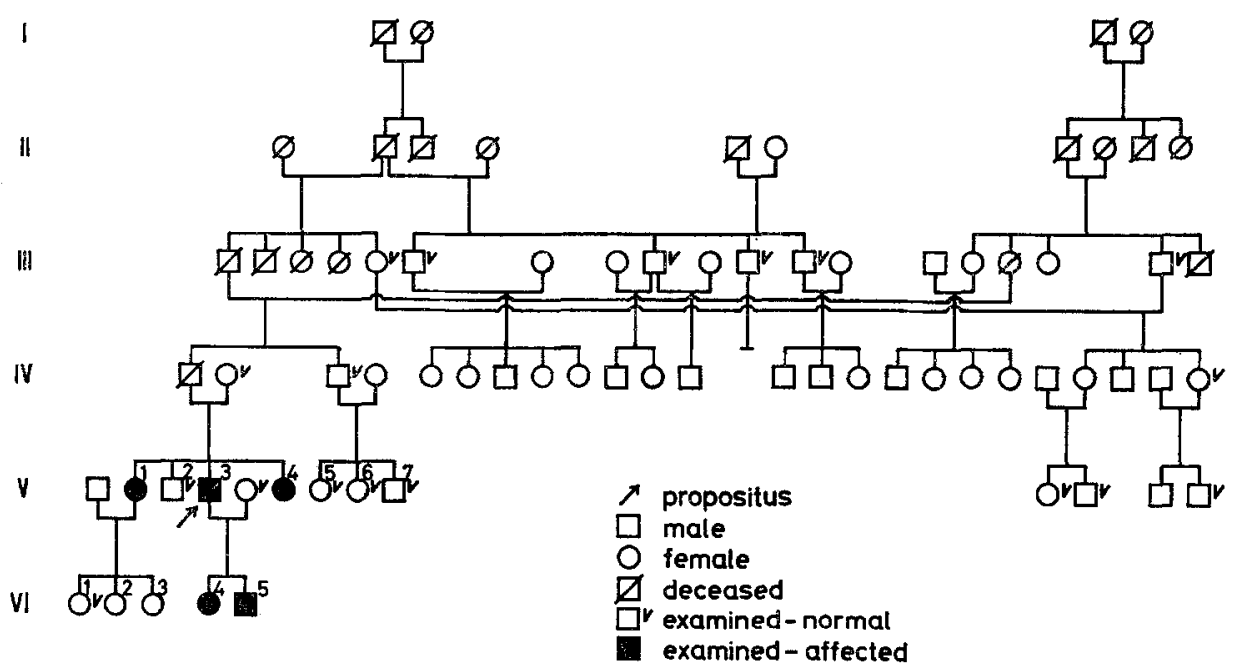

Fig. 1. Pedigree of a family afflicted with familial hypouricemia due to isolated renal tubular defect.

Vol. 26, No. 3, 1981 


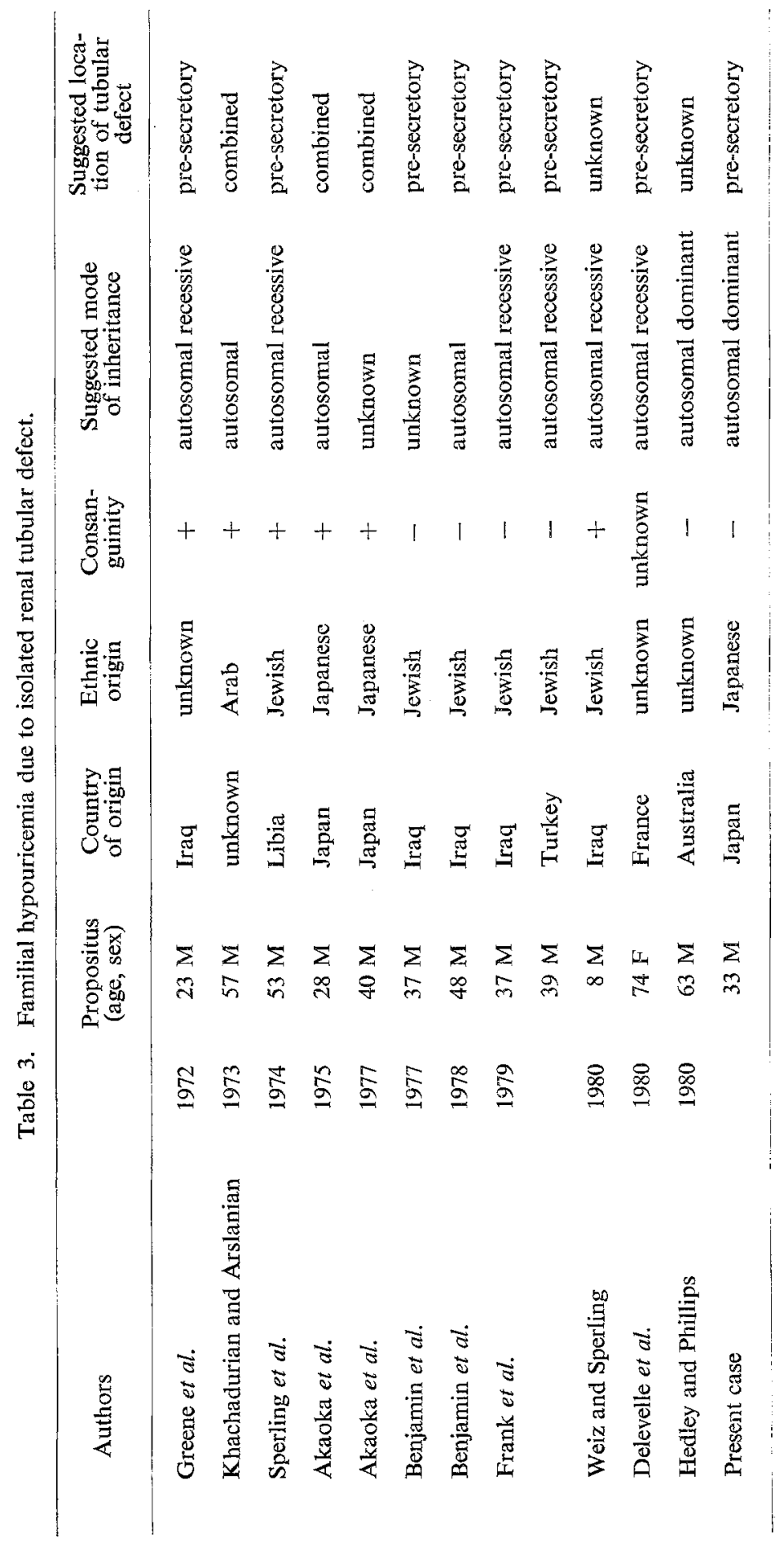

Jpn. J. Human Genet. 
As shown in Fig. 1, a survey of the available members of the proband's family (23 in 4 generations) revealed 4 additional hypouricemic subjects: 2 sisters (V-1, $1.0 \mathrm{mg} / \mathrm{dl}$ and $\mathrm{V}-4,2.0 \mathrm{mg} / \mathrm{dl}$ ) and 2 children (VI-4, 5 y.0., $1.2 \mathrm{mg} / \mathrm{dl}$ and VI-5, 3 y.o., $1.0 \mathrm{mg} / \mathrm{dl})$.

\section{DISCUSSION}

It is only recently that familial hypouricemia due to isolated renal tubular defect has been described in man. As shown in Table 3, twelve families with this condition have been reported so far. It is apt to occur in particular ethnic groups, i.e. Jewish and Japanese. It has been suggested that this inborn error is relatively common in non-Ashkenazi Jew (Frank et al., 1979; Weiz and Sperling, 1980). However, it has been reported in other ethnic groups and the recent increase in the number of reports suggests that it may be less uncommon than originally thought.

An autosomal, probably recessive mode of inheritance was documented or suggested in all previously reported families (Table 3). Autosomal dominant inheritance was reported recently, but the localization of the defect in urate handling was not determined (Hedley and Phillips, 1980). The mode of inheritance in the present family appears to be autosomal dominant because siblings and children of both sexes are affected and there is no consanguineous marriage.

The present concept of urate handling in the kidney proposes a four component model: glomerular filtration, pre-secretory tubular reabsorption, tubular secretion and post-secretory reabsorption (Rieselbach, 1977). Thus far three types of renal hypouricemia were classified according to the response of urate excretion to pyrazinamide and probenecid, i.e. due to defective proximal pre-secretory, post-secretory or combined tubular reabsorption of uric acid. Renal hypouricemia due to postsecretory defect, however, was found only in sporadic cases (Barrientos et al., 1979; Sorensen and Levinson, 1980). In the present case, the urate: creatinine clearance ratios were, though increased, less than 1 , and responses to pyrazinamide and probenecid were attenuated. According to de Vries and Sperling (1979), these findings may be taken to indicate that the tubular defect in urate handling most probably resides in the pre-secretory reabsorption site. To our knowledge, consequently, this is the first family afflicted with autosomal dominant familial hypouricemia due to an isolated defect in pre-secretory reabsorption of urate.

Results obtained with the pyrazinamide and probenecid tests in the various renal hypouricemic families indicate heterogeneity of the genetic abnormality in the tubular defect (De Vries and Sperling, 1979). The fact that there are two different patterns of inheritance in familial hypouricemia due to an isolated defect in presecretory reabsorption of urate suggests that tubular pre-secretory reabsorption of uric acid in man is under the control of at least two autosomal loci. Precise comparison of these two types of familial hypouricemia may reward us with further insights into the tubular transport of uric acid in man. 
Acknowledgements We are grateful to Drs. K. Suzuki and K. Kono, Institute of Tanabe Pharmaceutical Company, for determining oxypurines in serum. Our thanks are due to Drs. R. Chiba and N. Ishii, Fukushima Rosai Hospital, for allowing us to read clinicopathological records, and to Prof. J. Miller, University of British Columbia, for looking over the manuscript. We wish to extend special thanks to Dr. M. Kuroda, Takeda Chemical Industries Ltd., for his invaluable support.

\section{REFERENCES}

Akaoka, I., Nishizawa, T., Yano, E., Takeuchi, A., Nishida, Y., Yoshimura, T., and Horiuchi, Y. 1975. Familial hypouricemia due to renal tubular defect of urate transport. Ann. Clin. Res. 7: 318-324.

Akaoka, I., Nishizawa, T., Yano, E., Kamatani, N., and Nishida, Y. 1977. Renal urate excretion in five cases of hypouricemia with an isolated renal defect of urate transport. J. Rheum. 4:8694.

Barrientos, A., Perez-Diaz, V., Diaz-Gonzalez, R., and Rodicio, J.L. 1979. Hypouricemia by defect in the tubular reabsorption. Arch. Intern. Med. 139: 787-789.

Benjamin, D., Sperling, O., Weinberger, A., Pinkhas, J., and de Vries, A. 1977. Familial hypouricemia due to isolated renal tubular defect. Attenuated response of uric acid clearance to probenecid and pyrazinamide. Nephron 18: 220-225.

Benjamin, D., Sperling, O., Weinberger, A., and Pinkhas, J. 1978. Familial hypouricemia due to isolated renal tubular abnormality. Biomedicine 29: 54-56.

De Vries, A., and Sperling, O. 1979. Inborn hypouricemia due to isolated renal tubular defect. Biomedicine 30: 75-80.

Delevelle, F., Trombert, J.C., Bouvier, M.F., and Canarelli, G. 1980. Hypouricemie renale idiopathique. 1 Observation. Nouv. Presse Med. 9: 2578.

Frank, M., Many, M., and Sperling, O. 1979. Familial renal hypouricemia: two additional cases with uric acid lithiasis. Brit. J. Urol. 51: 88-91.

Greene, M.L., Marcus, R., Aurbach, G.D., Kazam, E.S., and Seegmiller, J.E. 1972. Hypouricemia due to isolated renal tubular defect. Dalmatian dog mutation in man. Am. J. Med. 53: 361367.

Hedley, J.M., and Phillips, P.J. 1980. Familial hypouricemia associated with renal tubular uricosuric and uric acid calculi: case report. J. Clin. Pathol. 33: 971-972.

Khachadurian, A.K., and Arslanian, M.J. 1973. Hypouricemia due to renal uricosuria. A case study. Ann. Intern. Med. 78: 547-550.

Nakamura, T. 1979. Clearance test of uric acid. Jpn. J. Clin. Med. (in Japanese) 37: 1768-1772.

Rieselbach, R.E. 1977. Renal handling of uric acid. Adv. exp. Med. Biol. 76B: 1-22.

Sorensen, L.B., and Levinson, D.J. 1980. Isolated defect in post-secretory reabsorption of uric acid. J. Rheum. Dis. 39: 180-183.

Sperling, O., Weinberger, A., Oliver, I., Liberman, U.A., and De Vries, A. 1974. Hypouricemia, hypercalciuria, and decreased bone density: A hereditary syndrome. Ann. Intern. Med. 80: $482-487$.

Steele, T.H., and Rieselbach, R.E. 1967. The renal mechanism for urate homeostasis in normal man. Am. J. Med. 43: 868-875.

Weiz, R., and Sperling, O. 1980. Hereditary renal hypouricemia. Isolated tubular defect of urate reabsorption. J. Pediat. 96: 850-853. 